\title{
Infant and young child feeding indicators across nine East and Southeast Asian countries: an analysis of National Survey Data 2000-2005
}

\author{
Michael J Dibley ${ }^{1, *}$, Upul Senarath ${ }^{2}$ and Kingsley E Agho ${ }^{3}$ \\ 'Sydney School of Public Health, The University of Sydney, Edward Ford Building (A27), NSW 2006, \\ Australia: ${ }^{2}$ Faculty of Medicine, Department of Community Medicine, University of Colombo, Sri Lanka: \\ ${ }^{3}$ School of Medicine, University of Western Sydney, Australia
}

Submitted 2 May 2009: Accepted 23 February 2010: First published online 4 May 2010

\begin{abstract}
Objective: To compare infant and young child feeding practices in children aged 0-23 months across nine East and Southeast Asian countries.

Design: Secondary analyses of cross-sectional data from available Demographic and Health Surveys (DHS; Indonesia, Philippines, Timor-Leste, Cambodia and Vietnam), Multiple Indicator Country Surveys (Lao People's Democratic Republic (Lao PDR) and Myanmar) and national nutrition surveys (Democratic People's Republic of Korea (DPR Korea) and Mongolia) conducted between 2000 and 2005.

Setting: Seven countries from Southeast Asia and two from East Asia.

Subjects: Children aged 0-23 months with samples ranging from 826 to 5610 for DHS, and from 477 to 5860 for non-DHS data.

Results: More than $93 \%$ of infants were ever breast-fed, and over $75 \%$ were currently breast-fed except in the Philippines. Timely initiation of breast-feeding varied from $32 \%$ in Indonesia to $46 \%$ in Timor-Leste. Exclusive breast-feeding (EBF) rate in infants under 6 months of age ranged from $11 \%$ in Myanmar to $60 \%$ in Cambodia. EBF rates were also low in Vietnam (15.5\%) and Lao PDR (23\%), and varied between $30 \%$ and $40 \%$ in Indonesia, Philippines and Timor-Leste. The proportion of infants under 6 months of age who were given breast milk with non-milk liquids was high except in Indonesia and Timor-Leste. Bottle-feeding rates were lower in DPR Korea (3\%), Lao PDR (6\%) and Myanmar (6\%) and higher in the Philippines (49\%) and Mongolia (31\%). Timely complementaryfeeding rate varied widely across countries (6-99\%).

Conclusions: All the countries studied should make greater efforts to improve timely initiation of breast-feeding and EBF for 6 months. Measures should be taken to reduce high bottle-feeding rate in the Philippines, Mongolia, Indonesia and Vietnam, and improve complementary-feeding rate in Lao PDR, Myanmar, DPR Korea and Philippines.
\end{abstract}

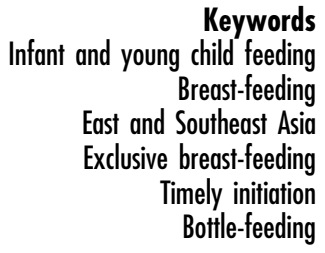

Suboptimal feeding practices in infancy and childhood have led to the high prevalence of malnutrition, increased morbidity and mortality in children in the developing world. It has been found that non-exclusive breast-feeding (EBF) in the first 6 months of life results in 1.4 million deaths and $10 \%$ of the disease burden in children younger than 5 years ${ }^{(1)}$. It is also estimated that the death of about $10-15 \%$ of infants $<5$ years old in resource-poor countries could be prevented through the achievement of $90 \%$ coverage with EBF alone ${ }^{(2)}$, and about $22 \%$ of neonatal deaths could be prevented if breast-feeding started within the first hour of birth ${ }^{(3)}$.

In keeping with the Millennium Development Goals, countries in the developing world have committed to reduce the mortality rate in $<5$-year-olds by two-thirds between 1990 and $2015^{(4)}$. Appropriate feeding of infants and young children is one of the feasible interventions in child survival programmes addressing this goal. The WHO infant feeding guidelines recommend that infants should be exclusively breast-fed for the first 6 months of life to achieve optimal growth, development and health ${ }^{(5)}$. Thereafter, to meet their evolving nutritional requirements, infants should receive nutritionally adequate and safe complementary foods while breastfeeding continues for up to 2 years of age or beyond. Breast-feeding should be initiated within the first hour of birth, and no other pre-lacteals or bottle-feeds should be given to the infant. 
Breast milk provides almost all the necessary nutrients, growth factors and immunological components for a healthy infant ${ }^{(6)}$. Appropriate breast-feeding has proven effective in reducing the incidence and severity of gastrointestinal and respiratory infections ${ }^{(7-11)}$. Other advantages of breast-feeding include the enhancement of cognitive development ${ }^{(12,13)}$, and prevention of allergies, obesity, hypertension and insulin-dependent diabetes mellitus. Health gains for breast-feeding mothers include lactational ameonorrhea, early involution of the uterus, enhanced bonding between the mother and the infant and reduction in the incidence of ovarian and breast cancer $^{(6)}$. From an economic perspective, breast-feeding is less expensive than breast milk substitutes ${ }^{(6)}$.

Despite numerous recognized advantages over artificial feeding, breast-feeding rates in most countries are typically low, and have only slowly improved. According to estimates between 1995 and 2003, only 38\% of infants in the developing world were exclusively breast-fed for the first 6 months ${ }^{(14)}$. Demographic and Health Surveys (DHS), Multiple Indicator Country Surveys (MICS) and national nutritional surveys (NNS) from East Asian countries provide information on infant and child feeding practices at a national level; however, there is limited information regarding cross-country comparisons of breast-feeding indicators in the region. A previous group has compiled an infant and young child feeding update using available key indicators from the DHS reports of countries around the world. However, this update includes only three countries - Cambodia, Indonesia and Philippines from the East Asian region ${ }^{(15)}$. In East Asia and Southeast Asia it is important to estimate all possible feeding indicators as recommended by the WHO, with a view of recognizing the countries and practices that need further intervention. A cross-country comparison has the advantage of describing variations in different dimensions of breast-feeding across countries. Such an analysis would help individual countries to identify the aspects of breast-feeding that deserve priority in their breast-feeding promotion programmes. The aim of this secondary data analysis was to assess and compare infant and young child feeding practices across nine East and Southeast Asian countries using the key indicators recommended by the $\mathrm{WHO}^{(16)}$.

\section{Methods}

\section{Data sources}

Our analysis was based mainly on available data sets of DHS and MICS collected between 2000 and 2005 in the East and Southeast Asian regions. DHS data were available for five countries - Indonesia 2002-2003 ${ }^{(17)}$, Philippines $2003^{(18)}$, Timor-Leste $2003^{(19)}$, Cambodia 2001 and $2005^{(20)}$ and Vietnam $2002^{(21)}$. Since these data, except Cambodia, were collected between 2002 and
2003, we assumed that the feeding practices remained relatively unchanged over the 2-year period. For Cambodia, only the 2005 data were used for the cross-country comparisons since our aim was to present the latest available data within the specified period. MICS data were available for Lao People's Democratic Republic (Lao $\mathrm{PDR}^{(22)}$ and Myanmar ${ }^{(23)}$ in 2000. There has been no DHS or MICS in the Democratic People's Republic of Korea (DPR Korea). Data from the 2002 National Nutrition Survey with similar variables to those used in the DHS surveys were used ${ }^{(24)}$. Similarly in Mongolia, the data from the 2002 National Nutrition Assessment were used, although it does not include all the variables available in other data sets ${ }^{(25)}$. All these surveys were nationally representative households surveys in which married women of reproductive age were interviewed by trained investigators.

The MICS programme developed by UNICEF assists countries in filling data gaps for monitoring the situation of children and women through statistically sound, internationally comparable estimates of socio-economic and health indicators. MICS are typically carried out by government organizations, with the technical support and financial assistance of UNICEF and its partners. UNICEF provides technical support and training through a series of regional workshops covering questionnaire content, sampling and survey implementation, data processing, data quality and data analysis, and report writing, data archiving and dissemination.

The relevant public domain data sets were downloaded and inspected for quality of data, completeness of information and comparability of variables required for the analysis. The required variables from each data set were selected and files were constructed for each country. These were merged into a central database with the data from all countries. The analysis was confined to the last born child aged 0-23 months living with the respondent. The details of survey methodology, sampling procedure and questionnaires are available in the respective DHS, MICS or NNS reports.

\section{Feeding indicators}

Infant feeding indicators were estimated according to the key breast-feeding and selected complementary-feeding indicators described by the WHO in $1991^{(16)}$. The estimated indicators were timely first-suckling rate, ever breast-fed rate, current breast-feeding rate, continued breast-feeding rate at $12-15$ and 20-23 months, EBF rate, predominant breast-feeding rate, full breast-feeding rate, bottle-feeding rate, timely complementary-feeding rate and the median duration of breast-feeding. Timely firstsuckling rate was based on mother's response to the question how soon after the birth was the child given breast milk, and ever breast-fed rate whether the child was given breast milk at least once at any time since birth. All other indicators were based on $24 \mathrm{~h}$ recall by the mother. 
The timely complementary-feeding rate was calculated using a method proposed in earlier recommendations by the $\mathrm{WHO}^{(16)}$.

\section{Data analysis}

Analyses were performed using the Stata statistical software package version 9.0 (Stata Corp., College Station, TX, USA) with 'Svy' commands to allow for adjustments for the cluster sampling design used in the surveys when estimating 95\% CI around prevalence estimates. A weighted total of 23702 children were included from the nine countries.

\section{Results}

\section{Basic characteristics of the samples}

Basic characteristics of the DHS and non-DHS (MICS and NNS) samples included in the study are summarized in Tables 1 and 2, respectively. The sample sizes ranged from 826 to 5610 for the DHS data, and from 477 to 5860 for nonDHS data sets. In all the data sets, both male and female infants and 6-month age categories were almost equally represented. The Mongolian sample did not include infants less than 6 months of age.

Among the DHS samples (Table 1), the proportion of mothers who had secondary or a higher level of education was low in Cambodia (16\%) and Timor-Leste (27\%), intermediate in Indonesia (50\%) and high in Vietnam (67\%) and the Philippines (70\%). Vietnam had a very high working mother population $(81 \%)$ when compared with the other countries. More than $88 \%$ of mothers had made at least one antenatal clinic visit during the pregnancy in Indonesia, Philippines and Vietnam. The trained assistance at delivery ranged from $16 \%$ in Timor-Leste to $75 \%$ in Vietnam. Almost $47 \%$ of mothers in Cambodia did not have any postnatal checkup, whereas the corresponding rate for Vietnam was $6 \%$. The proportion of women who participated in decision making for all of the five household decisions enquired by the survey was $58 \%$ in the Philippines, $64 \%$ in Indonesia and $72 \%$ in TimorLeste. According to mothers' perceptions, approximately $42-75 \%$ of the children from these countries were of average size at birth. Timor-Leste, Vietnam and Cambodia had predominantly rural households, whereas Indonesia and Philippines were distributed equally between urban and rural populations.

Limited information was available in the non-DHS samples (Table 2). The proportion of mothers who had secondary or a higher level of education ranged from $17 \%$ in Lao PDR to $76 \%$ in DPR Korea. Information on birth attendance was available only for Lao PDR and DPR Korea. The trained attendance was poor for both $(20 \%$ and $13 \%$, respectively). Myanmar, Mongolia and Lao PDR had above $60 \%$ rural households, whereas in the DPR Korea $59 \%$ were from urban households. According to mothers' perceptions, approximately $70-90 \%$ of these children were of average size at birth.

\section{Feeding indicators across the countries}

Tables 3 and 4 illustrate the estimated breast-feeding indicators for the nine East Asian countries included in the present study. More than $90 \%$ of the infants were ever breast-fed in all the countries under study, except in the Philippines, where the rate was $88 \%$. Almost all infants in Myanmar and Lao PDR were ever breast-fed. Information on timely initiation of breast-feeding was mainly limited to the five DHS and these rates varied from $32 \%$ in Indonesia to $46 \%$ in Timor-Leste.

When compared with other countries the current breast-feeding rate among children aged 0-23 months was found to be significantly lower in the Philippines (59\%). The current breast-feeding rates fell between $70 \%$ and $80 \%$ for Timor-Leste, Vietnam and DPR Korea, and between $80 \%$ and $90 \%$ for Indonesia, Cambodia, Lao PDR, Myanmar and Mongolia. The pattern of continued breast-feeding rate at $12-15$ months in each country was very similar to the country's current breast-feeding rate, but the continuation rate declined by about 30-40\% when the child reached 20-23 months. However, countries such as Myanmar (67\%), Indonesia (59\%), Cambodia (54\%) and Mongolia (66\%) sustained higher rates of continuation even at 20-23 months.

The EBF rate in infants of less than 6 months of age varied from $11 \%$ in Myanmar to $60 \%$ in Cambodia (Table 4). Lower EBF rates were reported in Vietnam (16\%) and Lao PDR (23\%). The rates in Indonesia, Philippines and Timor-Leste were between $30 \%$ and $40 \%$. As shown in Fig. 1, the proportion of infants aged $<6$ months who were given breast milk together with non-milk liquids (predominantly breast-fed) was high except in Indonesia and Timor-Leste.

Lower bottle-feeding rates were reported in DRP Korea (3\%), Lao PDR (6\%) and Myanmar (6\%). Higher bottle-feeding rates were reported in Philippines (49\%), Mongolia (31\%), Indonesia (23\%) and Vietnam (21\%). With respect to timely complementary feeding, the rate was more than $60 \%$ in the majority of the countries. However, there was a wide variation between countries. For example, it was as low as $6 \%$ in Myanmar and $10 \%$ in Lao PDR, and as high as $99 \%$ in Mongolia.

\section{Discussion}

Early initiation of breast-feeding has proven benefits ${ }^{(3)}$, thus we recommend that all the countries should make greater efforts to improve the practice of initiation of breast-feeding within the first hour of birth. Very high ever breast-fed rates across the region indicate that breastfeeding is universal in the East and Southeast Asian region. The proportion of currently breast-fed was also high, 
Table 1 Individual, household and community level characteristics of children 0-23 months of age, for five DHS surveys

\begin{tabular}{|c|c|c|c|c|c|}
\hline & Indonesia ( $n$ 5610) & Philippines ( $n$ 2491) & Timor-Leste ( $n$ 2166) & Cambodia (n 2953) & Vietnam ( $n$ 826) \\
\hline Characteristics & $\%$ & $\%$ & $\%$ & $\%$ & $\%$ \\
\hline \multicolumn{6}{|l|}{ Individual-level factors } \\
\hline \multicolumn{6}{|l|}{ Maternal working status } \\
\hline Non-working & $69 \cdot 0$ & $67 \cdot 3$ & $44 \cdot 1$ & $49 \cdot 3$ & $18 \cdot 6$ \\
\hline Working (past 12 months) & $31 \cdot 1$ & $32 \cdot 7$ & $55 \cdot 9$ & $50 \cdot 8$ & $81 \cdot 4$ \\
\hline \multicolumn{6}{|l|}{ Maternal education } \\
\hline No education & $4 \cdot 0$ & $1 \cdot 8$ & $44 \cdot 4$ & $23 \cdot 5$ & $6 \cdot 0$ \\
\hline Primary & $45 \cdot 8$ & $27 \cdot 9$ & $28 \cdot 2$ & $60 \cdot 2$ & $27 \cdot 0$ \\
\hline Secondary and above & $50 \cdot 2$ & $70 \cdot 4$ & $27 \cdot 4$ & $16 \cdot 3$ & $67 \cdot 0$ \\
\hline \multicolumn{6}{|l|}{ Mother's age } \\
\hline$\leq 24$ years & $33 \cdot 8$ & $31 \cdot 2$ & $22 \cdot 5$ & $35 \cdot 3$ & $35 \cdot 7$ \\
\hline $25-34$ years & $48 \cdot 1$ & $48 \cdot 8$ & $51 \cdot 7$ & $44 \cdot 0$ & $53 \cdot 8$ \\
\hline$\geq 35$ years & $18 \cdot 1$ & $20 \cdot 0$ & $25 \cdot 8$ & $20 \cdot 7$ & $10 \cdot 5$ \\
\hline \multicolumn{6}{|l|}{ Marital status } \\
\hline Currently married & $98 \cdot 6$ & $98 \cdot 1$ & $99 \cdot 3$ & $96 \cdot 1$ & $98 \cdot 3$ \\
\hline Formerly married & $1 \cdot 4$ & $1 \cdot 9$ & $0 \cdot 7$ & 3.9 & $1 \cdot 7$ \\
\hline \multicolumn{6}{|l|}{ Birth order } \\
\hline 1st born & $32 \cdot 7$ & $27 \cdot 9$ & $11 \cdot 4$ & $27 \cdot 4$ & $41 \cdot 7$ \\
\hline 2nd-4th & $55 \cdot 5$ & $49 \cdot 5$ & $46 \cdot 8$ & $52 \cdot 5$ & $54 \cdot 0$ \\
\hline 5th and above & $11 \cdot 8$ & $22 \cdot 6$ & $41 \cdot 8$ & $20 \cdot 1$ & $4 \cdot 3$ \\
\hline \multicolumn{6}{|l|}{ Preceding birth interval } \\
\hline No previous birth & $33 \cdot 0$ & $28 \cdot 1$ & $12 \cdot 0$ & $27 \cdot 7$ & $41 \cdot 9$ \\
\hline$<24$ months & $7 \cdot 5$ & $50 \cdot 9$ & $25 \cdot 7$ & $10 \cdot 3$ & $9 \cdot 3$ \\
\hline$\geq 24$ months & $59 \cdot 5$ & $21 \cdot 0$ & $62 \cdot 3$ & $62 \cdot 1$ & $48 \cdot 8$ \\
\hline \multicolumn{6}{|l|}{ Sex of baby } \\
\hline Male & $51 \cdot 9$ & $51 \cdot 3$ & $47 \cdot 8$ & $50 \cdot 7$ & $51 \cdot 1$ \\
\hline Female & $48 \cdot 1$ & $48 \cdot 7$ & $52 \cdot 2$ & $49 \cdot 3$ & $48 \cdot 9$ \\
\hline \multicolumn{6}{|l|}{ Age of child (months) } \\
\hline $0-5$ & $27 \cdot 5$ & $24 \cdot 2$ & $29 \cdot 5$ & $28 \cdot 3$ & $23 \cdot 5$ \\
\hline $6-11$ & $24 \cdot 1$ & $28 \cdot 8$ & $27 \cdot 1$ & $29 \cdot 1$ & $23 \cdot 0$ \\
\hline $12-17$ & $27 \cdot 0$ & $24 \cdot 3$ & $26 \cdot 3$ & $25 \cdot 6$ & $29 \cdot 6$ \\
\hline 18-23 & $21 \cdot 5$ & $22 \cdot 7$ & $17 \cdot 1$ & $17 \cdot 0$ & $23 \cdot 9$ \\
\hline \multicolumn{6}{|l|}{ Size of baby } \\
\hline Small & $13 \cdot 0$ & $19 \cdot 0$ & $7 \cdot 7$ & $15 \cdot 3$ & $10 \cdot 1$ \\
\hline Average & $55 \cdot 4$ & $59 \cdot 4$ & $70 \cdot 8$ & $41 \cdot 7$ & $74 \cdot 8$ \\
\hline Large & $31 \cdot 7$ & $21 \cdot 6$ & 8.9 & $43 \cdot 0$ & $15 \cdot 0$ \\
\hline Place of delivery & & & & & \\
\hline Home & $56 \cdot 2$ & $60 \cdot 1$ & $89 \cdot 7$ & $76 \cdot 5$ & $20 \cdot 9$ \\
\hline Health facility & $43 \cdot 8$ & $39 \cdot 9$ & $10 \cdot 3$ & $23 \cdot 5$ & $79 \cdot 1$ \\
\hline Mode of delivery & & & & & \\
\hline Non-Caesarean & $95 \cdot 5$ & $92 \cdot 0$ & $99 \cdot 7$ & $97 \cdot 8$ & $89 \cdot 6$ \\
\hline Caesarean section & $4 \cdot 5$ & $8 \cdot 0$ & $0 \cdot 3$ & $2 \cdot 3$ & $10 \cdot 5$ \\
\hline Type of delivery assistance & & & & & \\
\hline Health professional & $58 \cdot 3$ & $57 \cdot 5$ & $16 \cdot 1$ & $46 \cdot 6$ & $75 \cdot 0$ \\
\hline TBA & $30 \cdot 5$ & $35 \cdot 0$ & $8 \cdot 6$ & $50 \cdot 3$ & $3 \cdot 3$ \\
\hline Other & $11 \cdot 2$ & $7 \cdot 5$ & $75 \cdot 3$ & $3 \cdot 2$ & $21 \cdot 7$ \\
\hline Antenatal clinic visits & & & & & \\
\hline None & $4 \cdot 5$ & $5 \cdot 9$ & $36 \cdot 5$ & $26 \cdot 0$ & $11 \cdot 8$ \\
\hline $1-3$ & $14 \cdot 6$ & $25 \cdot 7$ & 33.5 & $46 \cdot 8$ & $56 \cdot 9$ \\
\hline$>4$ & $80 \cdot 9$ & $68 \cdot 4$ & $30 \cdot 0$ & $26 \cdot 9$ & $31 \cdot 4$ \\
\hline Timing of postnatal checkup & & & & & \\
\hline Immediate & $43 \cdot 8$ & $39 \cdot 9$ & & $24 \cdot 4$ & $79 \cdot 1$ \\
\hline $0-2 d$ & $34 \cdot 3$ & $19 \cdot 6$ & & $6 \cdot 6$ & $2 \cdot 9$ \\
\hline $3-6 d$ & $7 \cdot 6$ & $10 \cdot 0$ & & $31 \cdot 6$ & $10 \cdot 2$ \\
\hline Day 7 or later & $4 \cdot 6$ & $8 \cdot 7$ & & $37 \cdot 5$ & $2 \cdot 1$ \\
\hline No checkups & $9 \cdot 8$ & $21 \cdot 7$ & & $46 \cdot 6$ & $5 \cdot 8$ \\
\hline Household-level factors & & & & & \\
\hline Household wealth index & & & & & \\
\hline Poorest (lowest quintile) & $22 \cdot 1$ & $26 \cdot 3$ & $42 \cdot 0$ & $27 \cdot 1$ & $32 \cdot 1$ \\
\hline Poorer & $18 \cdot 8$ & $22 \cdot 7$ & & $23 \cdot 3$ & $37 \cdot 1$ \\
\hline Middle & $19 \cdot 7$ & $19 \cdot 9$ & $39 \cdot 7$ & $18 \cdot 8$ & $30 \cdot 8$ \\
\hline Richer & $20 \cdot 0$ & $17 \cdot 6$ & & $16 \cdot 7$ & \\
\hline Richest (highest quintile) & $19 \cdot 4$ & $13 \cdot 6$ & $18 \cdot 3$ & $14 \cdot 1$ & $32 \cdot 2$ \\
\hline Decisions that women have final say & & & & & $54 \cdot 0$ \\
\hline None & $0 \cdot 8$ & $2 \cdot 7$ & $0 \cdot 1$ & $25 \cdot 7$ & $13 \cdot 8$ \\
\hline $1-2$ & $5 \cdot 6$ & $13 \cdot 7$ & 4.9 & $49 \cdot 8$ & \\
\hline $3-4$ & $29 \cdot 6$ & $25 \cdot 5$ & $23 \cdot 4$ & $12 \cdot 5$ & \\
\hline 5 & $63 \cdot 9$ & $58 \cdot 1$ & $71 \cdot 6$ & $12 \cdot 0$ & \\
\hline Community level factors & & & & & \\
\hline Residence & & & & & \\
\hline Urban & $47 \cdot 2$ & $50 \cdot 1$ & & $12 \cdot 3$ & $18 \cdot 0$ \\
\hline Rural & $52 \cdot 8$ & $49 \cdot 9$ & & $87 \cdot 7$ & $82 \cdot 0$ \\
\hline
\end{tabular}

DHS, Demographic and Health Survey; TBA, traditional birth attendant. 
Table 2 Individual, household and community level characteristics of children at 0-23 months of age, for MICS and other surveys

\begin{tabular}{|c|c|c|c|c|}
\hline & Lao PDR ( $n$ 1959) & Myanmar ( $n$ 5860) & DPR Korea ( $n$ 1360) & Mongolia ( $n$ 477) \\
\hline Characteristic & $\%$ & $\%$ & $\%$ & $\%$ \\
\hline \multicolumn{5}{|l|}{ Individual-level factors } \\
\hline \multicolumn{5}{|l|}{ Maternal working status } \\
\hline Non-working & & & & $55 \cdot 8$ \\
\hline Working (past 12 months) & & & & $44 \cdot 3$ \\
\hline \multicolumn{5}{|l|}{ Maternal education } \\
\hline No education & $42 \cdot 6$ & $15 \cdot 1$ & & $2 \cdot 6$ \\
\hline Primary & $39 \cdot 7$ & $54 \cdot 4$ & & $3 \cdot 7$ \\
\hline Secondary and above & $16 \cdot 8$ & $30 \cdot 5$ & $76 \cdot 4$ & $93 \cdot 6$ \\
\hline Non-standard & 0.9 & & $23 \cdot 5$ & \\
\hline \multicolumn{5}{|l|}{ Mother's age } \\
\hline$\leq 24$ years & $37 \cdot 2$ & $30 \cdot 2$ & $11 \cdot 2$ & $31 \cdot 2$ \\
\hline $25-34$ years & $45 \cdot 4$ & $48 \cdot 7$ & $84 \cdot 0$ & $57 \cdot 9$ \\
\hline$\geq 35$ years & $17 \cdot 3$ & $21 \cdot 1$ & $4 \cdot 8$ & $10 \cdot 9$ \\
\hline \multicolumn{5}{|l|}{ Marital status } \\
\hline Currently married & $95 \cdot 2$ & $83 \cdot 2$ & & $82 \cdot 9$ \\
\hline Formerly married & $4 \cdot 8$ & $16 \cdot 8$ & & $17 \cdot 2$ \\
\hline \multicolumn{5}{|l|}{ Sex of baby } \\
\hline Male & $48 \cdot 5$ & $48 \cdot 8$ & $50 \cdot 5$ & $56 \cdot 1$ \\
\hline Female & $51 \cdot 6$ & $51 \cdot 2$ & $49 \cdot 5$ & $43 \cdot 9$ \\
\hline \multicolumn{5}{|l|}{ Age of child (months) } \\
\hline $0-5$ & $28 \cdot 0$ & $25 \cdot 5$ & $17 \cdot 4$ & $34 \cdot 7$ \\
\hline $6-11$ & $24 \cdot 7$ & $28 \cdot 2$ & $35 \cdot 4$ & $35 \cdot 1$ \\
\hline $12-17$ & $27 \cdot 5$ & $25 \cdot 0$ & $25 \cdot 9$ & $30 \cdot 3$ \\
\hline $18-23$ & $19 \cdot 8$ & $21 \cdot 3$ & $21 \cdot 3$ & \\
\hline \multicolumn{5}{|l|}{ Size of baby } \\
\hline Small & $10 \cdot 2$ & & $5 \cdot 1$ & $4 \cdot 7$ \\
\hline Average & $80 \cdot 2$ & & $68 \cdot 6$ & $90 \cdot 3$ \\
\hline Large & $9 \cdot 7$ & & $68 \cdot 6$ & $5 \cdot 1$ \\
\hline \multicolumn{5}{|l|}{ Type of delivery assistance } \\
\hline Health professional & $19 \cdot 6$ & & $13 \cdot 3$ & \\
\hline TBA & $16 \cdot 1$ & & $0 \cdot 6$ & \\
\hline Other & $64 \cdot 3$ & & $0 \cdot 6$ & \\
\hline \multicolumn{5}{|l|}{ Household-level factors } \\
\hline \multicolumn{5}{|l|}{ Household wealth index } \\
\hline Poorest (lowest quintile) & $25 \cdot 7$ & $27 \cdot 2$ & & $64 \cdot 7$ \\
\hline Poorer & $22 \cdot 3$ & $22 \cdot 7$ & & \\
\hline Middle & $17 \cdot 5$ & $18 \cdot 6$ & & $26 \cdot 5$ \\
\hline Richer & $17 \cdot 6$ & $17 \cdot 0$ & & \\
\hline Richest (highest quintile) & $16 \cdot 8$ & $14 \cdot 5$ & & $8 \cdot 8$ \\
\hline \multicolumn{5}{|l|}{ Community level factors } \\
\hline \multicolumn{5}{|l|}{ Residence } \\
\hline Urban & $21 \cdot 1$ & $21 \cdot 3$ & $59 \cdot 4$ & $60 \cdot 3$ \\
\hline Rural & $78 \cdot 9$ & $78 \cdot 6$ & $40 \cdot 6$ & $39 \cdot 7$ \\
\hline
\end{tabular}

MICS, Multiple Indicator Country Survey; Lao PDR, Lao People's Democratic Republic; DPR Korea, Democratic People's Republic of Korea; TBA, traditional birth attendant.

especially during the first year of life. These observations are favourable indications as far as breast-feeding promotion is concerned, and warrant the need to focus on aspects such as timeliness, exclusiveness and continuity of breast-feeding. According to WHO recommendations, breast-feeding should be continued through the second year ${ }^{(5)}$. The present analysis revealed that, in all nine countries studied, the majority of mothers continued breast-feeding beyond the first year. However, it is important to take measures to sustain this rate until the end of the second year.

The EBF rates in all the countries should be improved in order to gain the full benefits of EBF that ultimately lead to a reduction in deaths among infants $<5$ years old $^{(2)}$. This could be achieved through breast-feeding promotion programmes by highlighting the importance of giving breast milk alone, and nothing else including plain water. It is important to note that even though EBF is low, a very high proportion of infants in countries like Lao PDR and Myanmar were fed with non-milk liquids in addition to breast milk. Hence, breast-feeding (giving only breast milk or breast milk and water) was high in Cambodia, Lao PDR and Myanmar despite low EBF. In contrast, the practice of giving non-milk liquids in Indonesia and Timor-Leste was minimal. The countries that reported very low EBF such as Myanmar, Vietnam and Lao PDR could make a substantial improvement in the EBF rate by avoiding the practice of giving water or other non-milk liquids in addition to breast milk.

Bottle-fed infants are at a higher risk of having infections and lower cognitive capacity ${ }^{(8,13)}$. It is important to 
Table 3 Timely first-suckling, ever breast-fed, current breast-feeding and continued breast-feeding rates in East and Southeast Asian countries (2000-2005)

\begin{tabular}{|c|c|c|c|c|c|c|c|c|c|c|}
\hline \multirow[b]{2}{*}{ Country } & \multicolumn{2}{|c|}{ Timely first-suckling rate } & \multicolumn{2}{|c|}{ Ever breast-fed rate } & \multicolumn{2}{|c|}{ Current breast-feeding rate } & \multicolumn{2}{|c|}{ Continued breast-feeding rate (1 year) } & \multicolumn{2}{|c|}{ Continued breast-feeding rate (2 years) } \\
\hline & $\%$ & $95 \% \mathrm{Cl}$ & $\%$ & $95 \% \mathrm{Cl}$ & $\%$ & $95 \% \mathrm{Cl}$ & $\%$ & $95 \% \mathrm{Cl}$ & $\%$ & $95 \% \mathrm{Cl}$ \\
\hline Indonesia & $31 \cdot 9$ & $28 \cdot 5,35 \cdot 4$ & $97 \cdot 5$ & $96 \cdot 3,98 \cdot 3$ & $82 \cdot 6$ & $80 \cdot 4,84 \cdot 6$ & $84 \cdot 7$ & $80 \cdot 9,87 \cdot 8$ & $58 \cdot 8$ & $53 \cdot 1,64 \cdot 2$ \\
\hline Philippines & $43 \cdot 6$ & $40 \cdot 7,46 \cdot 5$ & $88 \cdot 0$ & $86 \cdot 0,89 \cdot 7$ & $59 \cdot 3$ & $57 \cdot 2,61 \cdot 4$ & $56 \cdot 5$ & $51 \cdot 5,61 \cdot 4$ & $32 \cdot 8$ & $28 \cdot 2,37 \cdot 8$ \\
\hline Timor-Leste & $46 \cdot 1$ & $43 \cdot 0,49 \cdot 2$ & $97 \cdot 6$ & $96 \cdot 8,98 \cdot 2$ & $77 \cdot 9$ & $76 \cdot 1,79 \cdot 6$ & $72 \cdot 4$ & $68 \cdot 4,76 \cdot 1$ & $32 \cdot 5$ & $26 \cdot 5,39 \cdot 2$ \\
\hline Cambodia & $36 \cdot 4$ & $33 \cdot 5,39 \cdot 4$ & 98.9 & $97 \cdot 9,99 \cdot 5$ & $85 \cdot 3$ & $83 \cdot 3,86 \cdot 9$ & $89 \cdot 9$ & $86 \cdot 2,92 \cdot 7$ & $54 \cdot 4$ & $48 \cdot 4,60 \cdot 3$ \\
\hline Vietnam & $45 \cdot 6$ & $40 \cdot 1,51 \cdot 1$ & $96 \cdot 5$ & $94 \cdot 1,98 \cdot 0$ & $75 \cdot 3$ & $71 \cdot 7,78 \cdot 8$ & $81 \cdot 5$ & $71 \cdot 6,88 \cdot 5$ & $27 \cdot 9$ & $20 \cdot 0,37 \cdot 6$ \\
\hline Lao PDR & & & $99 \cdot 4$ & $98 \cdot 6,99 \cdot 7$ & $83 \cdot 5$ & $81 \cdot 7,85 \cdot 1$ & $82 \cdot 1$ & $78 \cdot 1,85 \cdot 5$ & $47 \cdot 4$ & $41 \cdot 4,53 \cdot 6$ \\
\hline Myanmar & & & $99 \cdot 9$ & $99 \cdot 8,99 \cdot 9$ & $89 \cdot 8$ & $88 \cdot 8,90 \cdot 7$ & $89 \cdot 0$ & $86 \cdot 6,91 \cdot 0$ & $67 \cdot 4$ & $63 \cdot 2,71 \cdot 4$ \\
\hline DPR Korea & & & $96 \cdot 6$ & $95 \cdot 1,97 \cdot 6$ & $76 \cdot 5$ & $74 \cdot 5,78 \cdot 4$ & $64 \cdot 6$ & $59 \cdot 5,69 \cdot 3$ & $33 \cdot 2$ & $27 \cdot 7,39 \cdot 1$ \\
\hline Mongolia* & & & $93 \cdot 1$ & $87 \cdot 7,96 \cdot 3$ & $82 \cdot 3$ & $78 \cdot 0,85 \cdot 9$ & $83 \cdot 8$ & $72 \cdot 3,91 \cdot 1$ & $66 \cdot 2$ & $53 \cdot 0,77 \cdot 2$ \\
\hline
\end{tabular}

Lao PDR, Lao People's Democratic Republic; DPR Korea, Democratic People's Republic of Korea.

${ }^{*}$ For Mongolia, data were available for children at 6-23 months of age.

Table 4 Exclusive breast-feeding, predominant breast-feeding, full breast-feeding, bottle-feeding and timely complementary-feeding rates in East and Southeast Asian countries (2000-2005)

\begin{tabular}{|c|c|c|c|c|c|c|c|c|c|c|}
\hline \multirow[b]{2}{*}{ Country } & \multicolumn{2}{|c|}{ Exclusive breast-feeding rate } & \multicolumn{2}{|c|}{ Predominant breast-feeding rate } & \multicolumn{2}{|c|}{ Full breast-feeding rate } & \multicolumn{2}{|c|}{ Bottle-feeding rate } & \multicolumn{2}{|c|}{ Timely complementary-feeding rate } \\
\hline & $\%$ & $95 \% \mathrm{Cl}$ & $\%$ & $95 \% \mathrm{Cl}$ & $\%$ & $95 \% \mathrm{Cl}$ & $\%$ & $95 \% \mathrm{Cl}$ & $\%$ & $95 \% \mathrm{Cl}$ \\
\hline Indonesia & 38.9 & $35 \cdot 0,43 \cdot 0$ & $6 \cdot 9$ & $5 \cdot 3,8 \cdot 9$ & $45 \cdot 8$ & $41 \cdot 9,49 \cdot 7$ & $23 \cdot 3$ & $20 \cdot 5,26 \cdot 4$ & $75 \cdot 4$ & $69 \cdot 8,80 \cdot 3$ \\
\hline Philippines & $33 \cdot 7$ & $30 \cdot 0,37 \cdot 6$ & $20 \cdot 4$ & $17 \cdot 2,24 \cdot 1$ & $54 \cdot 1$ & $49 \cdot 9,58 \cdot 2$ & $48 \cdot 7$ & $45 \cdot 8,51 \cdot 5$ & $61 \cdot 1$ & $56 \cdot 6,65 \cdot 4$ \\
\hline Timor-Leste & $30 \cdot 7$ & $27 \cdot 2,34 \cdot 5$ & $7 \cdot 7$ & $5 \cdot 7,10 \cdot 4$ & $38 \cdot 4$ & $34 \cdot 0,43 \cdot 1$ & $12 \cdot 5$ & $11 \cdot 0,14 \cdot 2$ & $82 \cdot 0$ & $76 \cdot 3,84 \cdot 6$ \\
\hline Cambodia & $60 \cdot 1$ & $55 \cdot 6,64 \cdot 3$ & $22 \cdot 8$ & $19 \cdot 6,26 \cdot 3$ & $82 \cdot 8$ & $79 \cdot 5,85 \cdot 8$ & $11 \cdot 2$ & $9 \cdot 4,13 \cdot 4$ & $80 \cdot 8$ & $60 \cdot 6,70 \cdot 2$ \\
\hline Vietnam & $15 \cdot 5$ & $10 \cdot 4,22 \cdot 5$ & $36 \cdot 9$ & $28 \cdot 0,46 \cdot 9$ & $52 \cdot 4$ & $43 \cdot 2,61 \cdot 5$ & $21 \cdot 1$ & $16 \cdot 9,26 \cdot 2$ & $86 \cdot 4$ & $77 \cdot 5,92 \cdot 2$ \\
\hline Lao PDR & $22 \cdot 5$ & $19 \cdot 3,26 \cdot 2$ & $57 \cdot 8$ & $53 \cdot 6,61 \cdot 8$ & $80 \cdot 3$ & $76 \cdot 8,83 \cdot 4$ & $5 \cdot 5$ & $4 \cdot 3,7 \cdot 1$ & $10 \cdot 3$ & $7 \cdot 5,14 \cdot 0$ \\
\hline Myanmar & $11 \cdot 0$ & $9 \cdot 2,13 \cdot 2$ & $65 \cdot 7$ & $63 \cdot 9,70 \cdot 6$ & $76 \cdot 7$ & $73 \cdot 9,79 \cdot 3$ & $5 \cdot 8$ & $4 \cdot 9,6 \cdot 9$ & $5 \cdot 5$ & $4 \cdot 1,7 \cdot 4$ \\
\hline DPR Korea & $52 \cdot 1$ & $46 \cdot 3,57 \cdot 9$ & $32 \cdot 9$ & $27 \cdot 8,38 \cdot 5$ & $85 \cdot 0$ & $80 \cdot 1,88 \cdot 9$ & $3 \cdot 0$ & $2 \cdot 0,4 \cdot 4$ & $44 \cdot 4$ & $39 \cdot 7,49 \cdot 1$ \\
\hline Mongolia* & & & & & & & $31 \cdot 4$ & $24 \cdot 3,39 \cdot 5$ & 98.5 & $94 \cdot 8,99 \cdot 6$ \\
\hline
\end{tabular}

Lao PDR, Lao People's Democratic Republic; DPR Korea, Democratic People's Republic of Korea.

${ }^{*}$ For Mongolia, data were available for children at 6-23 months. 


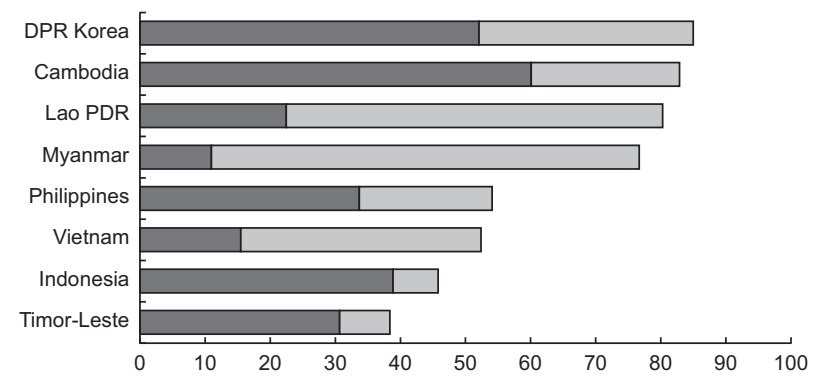

Fig. 1 Percentage of infants $<6$ months of age who were exclusively breast-fed $(\square)$ or received breast milk with non-milk liquids, i.e. predominant breast-feeding ( $\square$ ), across East and Southeast Asian countries (2000-2005) (DPR Korea, Democratic People's Republic of Korea; Lao PDR, Lao People's Democratic Republic)

adopt policies and practices to avoid the use of feeding bottles in infants unless medically indicated. Countries with high bottle-feeding rates such as the Philippines, Mongolia, Indonesia and Vietnam should identify target groups, i.e. socio-economically better-off women, in order to change the practice of bottle-feeding. Bottlefeeding rates rise with the socio-economic development. Countries with lower bottle-feeding rates, such as Lao PDR, Myanmar and DPR Korea, should try to sustain these low rates.

Lao PDR and Myanmar will need to educate families about the introduction of solid or semi-solid feeds to infants from 6 to 9 months. Although the timelines are satisfactory in many countries, these findings should be carefully interpreted with consideration to the adequacy and quality of feeds given to infants. A timely complementary-feeding rate based on $24 \mathrm{~h}$ dietary recall does not actually reflect the timing of the introduction of complementary food, because it can include those who have started complementary feeding even before the sixth month. In addition, this indicator alone is insufficient to comment about the adequacy of feeding frequency, energy density and quality of the diet, including sufficient micronutrients.

The main strengths of the present study were the nationally representative samples, the comprehensive data on standard infant feeding indicators and the appropriate adjustments for sampling design made in the analysis. One limitation would be the subjectivity of information in recalling the time of first suckling especially among mothers of older infants. This study was restricted to a description of the breast-feeding indicators at a national level. However, it is important to observe the variation of each indicator across different individual, household and community characteristics in the respective country. It is also important to identify the significant predictors of poor practices in each country. Such information would help the respective countries to target women for breast-feeding promotion programmes.
The main limitation of this comparison is the different years the surveys were conducted between 2000 and 2005. The infant and young child feeding practices could have changed in some countries due to programmatic activities or for other reasons. For example, in Cambodia there were remarkable improvements in many of the feeding indicators between 2000 and 2005 related to new infant and young child feeding programmes conducted by the Ministry of Health with support from $\mathrm{UNICEF}^{(20,26)}$. Similarly, caution should be taken when comparing data from different types of surveys - DHS, MICS and other national nutrition surveys. However, the questions used in the DHS and MICS surveys for infant feeding indicators were almost identical and the greatest differences in the manner the data were collected were found with the national nutrition surveys, e.g. the data available from Mongolia were for children 6-23 months of age, which prevented calculation of a number of indicators including exclusive and predominant breastfeeding rates.

In conclusion, all the countries should make greater efforts to improve the practice of initiation of breastfeeding within the first hour of birth. The EBF rates in all the countries should be improved by emphasizing the importance of giving breast milk alone and nothing else, including plain water, during the first 6 months of life. Countries with higher bottle-feeding rates should identify those groups at risk of bottle-feeding in order to implement targeted interventions. Further analysis would be required to disaggregate each indicator by different individual, household and community characteristics and to identify the significant predictors of poor practices in each country.

\section{Acknowledgements}

The financial support for the study was provided by the UNICEF East Asia/Pacific under the agreement SSA/ THLA/2006/00000422-0. The views expressed in this publication do not necessarily reflect those of UNICEF. The authors declare that there is no conflict of interests. M.J.D. generated the concept of study, designed the plan of analysis and edited the manuscript. U.S. compiled the tables and prepared the manuscript. K.E.A. downloaded the data and conducted the data analysis. The authors thank Dr Milana Votrubec of the University of Sydney for English language editing of the manuscript.

\section{References}

1. Black RE, Allen LH, Bhutta ZA et al. (2008) Maternal and child undernutrition: global and regional exposures and health consequences. Lancet 371, 243-260.

2. Jones G, Steketee RW, Black RE et al. (2003) How many child deaths can we prevent this year? Lancet 362, 65-71. 
3. Edmond KM, Zandoh C, Quigley MA et al. (2006) Delayed breastfeeding initiation increases risk of neonatal mortality. Pediatrics 117, e380-e386.

4. United Nations (2005) The Millennium Development Goals Report. New York: United Nations.

5. World Health Organization (2002) Infant and Young Child Nutrition; Global Strategy on Infant and Young Child Feeding. Geneva: WHO.

6. Leung AK \& Sauve RS (2005) Breast is best for babies. J Natl Med Assoc 97, 1010-1019.

7. Arifeen S, Black RE, Antelman G et al. (2001) Exclusive breastfeeding reduces acute respiratory infection and diarrhea deaths among infants in Dhaka slums. Pediatrics 108, E67.

8. Dewey K, Heinig MJ \& Nommsen-Rivers L (1995) Differences in morbidity between breast-fed and formulafed infants. J Pediatrics 126, Part 1, 696-702.

9. Howie PW, Forsyth JS, Ogston SA et al. (1990) Protective effect of breast feeding against infection. BMJ 300, $11-16$.

10. Wright AL, Holberg CJ, Martinez FD et al. (1989) Breast feeding and lower respiratory tract illness in the first year of life. Group Health Medical Associates. BMJ 299, 946-949.

11. Senarath U, Dibley MJ \& Agho KE (2007) Breast-feeding performance index: a composite index to describe overall breast-feeding performance among infants under 6 months of age. Public Health Nutr 10, 996-1004.

12. Richards M, Hardy R \& Wadsworth ME (2002) Long-term effects of breast-feeding in a national birth cohort: educational attainment and midlife cognitive function. Public Health Nutr 5, 631-635.

13. Temboury MC, Otero A, Polanco I et al. (1994) Influence of breast-feeding on the infant's intellectual development. J Pediatr Gastroenterol Nutr 18, 32-36.

14. UNICEF (2005) Childhood Under Threat: State of the World's Children 2005. New York: UNICEF.

15. Mukuria AG, Kothari MT \& Abderrahim N (2006) Infant and Young Child Feeding Updates. Calverton, MA: ORC Macro.
16. World Health Organization (1991) Indicators for Assessing Breast-Feeding Practices: Report of an Informal Meeting. Geneva: WHO

17. Badan Pusat Statistik-Statistics Indonesia (BPS) and ORC Macro (2003) Indonesia Demographic and Health Survey 2002-2003. Calverton, MA: BPS and ORC Macro.

18. National Statistics Office and ORC Macro (2003) Philippines Demographic and Health Survey 2003. Manila, Philippines and Calverton, MA: ORC Macro.

19. Ministry of Health and National Statistics Office Timor-Leste, The Australian National University, University of Newcastle \& ACIL Australia Pty Ltd (2004) Timor-Leste 2003 Demographic and Health Survey. Newcastle: University of Newcastle.

20. National Institute of Public Health, National Institute of Statistics (Cambodia) \& ORC Macro (2006) Cambodia Demographic and Health Survey 2005. Phnom Penh, Cambodia and Calverton, MA: National Institute of Public Health, National Institute of Statistics \& ORC Macro.

21. Committee for Population Family and Children (Vietnam) and ORC Macro (2003) Vietnam Demographic and Health Survey 2002. Calverton, MA: Committee for Population, Family and Children and ORC Macro.

22. National Statistics Centre (2000) Lao PDR Multiple Indicator Cluster Survey 2000. Vientiane, Lao PDR: National Statistics Centre.

23. Department of Health Planning of Ministry of Health (2000) Myanmar Multiple Indicator Cluster Survey (MICS) 2000. Myanmar: Department of Health Planning, Ministry of Health.

24. Central Bureau of Statistics (2003) Report on the DPR Korea Nutrition Assessment 2002. Pyongyang: Central Bureau of Statistics, DPR Korea.

25. Nutrition Research Center Ministry of Health and UNICEF (2002) Survey on the Nutritional Status of Children Under 2 years, Mongolia. Nutrition Research Center Ministry of Health and UNICEF: Mongolia.

26. UNICEF (2008) Mother support group network promotes exclusive breastfeeding in Cambodia. http://www.unicef. org/infobycountry/cambodia_43437.html (accessed June 2009). 